\title{
Silver(I) salts as useful reagents in pyrazole synthesis
}

\author{
Giorgio Molteni \\ Università degli Studi di Milano, Dipartimento di Chimica Organica e Industriale, via Golgi 19, \\ 20133 Milano, Italy \\ E-mail: giorgio.molteni@,unimi.it
}

Dedicated to Professor Luisa Garanti

\begin{abstract}
This account provides a survey on the synthesis of a huge variety of pyrazole-containing molecules by 1,3-dipolar cycloadditions promoted by silver(I) salts. The data on this subject are listed in a systematic way according to the type of the cycloaddition involved, with an emphasis to improvements with respect to reactions performed in the presence of the usual organic basic agents.
\end{abstract}

Keywords: Silver carbonate, silver acetate, 4,5-dihydropyrazoles, nitrilimine cycloaddition, diazoketone cycloadditions

\section{Contents}

1. Introduction

2. Intermolecular cycloadditions

3. Intramolecular cycloadditions

3.1 Formation of pyrazoles annulated to a five- or six- membered ring

3.2 Formation of pyrazoles annulated to a medium-sized ring

3.3 Formation of pyrazoles annulated to a large-sized ring

4. Stereoselective cycloadditions

4.1 Intermolecular stereoselective cycloadditions

4.2 Intramolecular stereoselective cycloadditions 


\section{Introduction}

Due to its wide occurrence in the field of heterocyclic chemistry, ${ }^{1}$ the pyrazole ring constitutes a relevant synthetic target in both academia and industry. In fact, such a heterocyclic moiety represents the core structure of a number of drugs, ${ }^{2}$ including the widely prescribed Celebrex and Viagra. ${ }^{3}$ Among the various synthetic routes which are amenable for the preparation of substituted pyrazoles, ${ }^{4}$ the cycloadditive method occupies a prominent place due to its versatility in the construction of complex heterocycles. ${ }^{5}$ To this respect, 1,3-dipolar species which have been traditionally exploited in pyrazole synthesis are diazocompounds ${ }^{6}$ and nitrilimines. ${ }^{7}$ These latter are well-known labile intermediates ${ }^{8}$ which are generated in situ in the presence of the dipolarophile as beautifully described from early works by Huisgen. ${ }^{9}$ The classical way followed in order to generate the nitrilimine implies the base-promoted dehydrohalogenation of the corresponding hydrazonoyl halides. This step is usually carried out in homogeneous conditions by using an organic base fully soluble in the reaction medium, which involves deprotonation of the NH group and subsequent loss of the halide ion. ${ }^{7}$ The aim of the present account is to describe the synthesis of pyrazole-containing molecules by means of an 1,3-dipolar cycloaddition as the key step, in which the generation of the reactive species is promoted by a non-conventional basic agent, namely silver(I) salts, in heterogeneous conditions.

\section{Intermolecular cycloadditions}

An early report describing the behaviour of silver(I) carbonate as an efficient enhancer of hydrazonoyl halides reactivity was concerned to the synthesis of cyclopropa $[c]$ cinnolines by way of an 1,7-electrocyclisation of $N$-(2-vinylphenyl)-substituted nitrilimines. ${ }^{10}$

The application of such reagent to the intermolecular nitrilimine cycloaddition were first exploited onto allylic alcohols as dipolarophiles (Scheme 1). ${ }^{11}$ The expected pyrazolinic cycloadducts 3 and 4 were obtained with low combined yields (10-28\%) with respect to the similar reaction between allyl alcohol and diphenylnitrilimine $(80 \%){ }^{12}$ These results may appear, prima facie, disappointing. However, the formation of open-chain products $\mathbf{5}$ gave some useful mechanistic insights about the reaction occurring between $\mathbf{1}$ and $\mathbf{2}$ in the presence of silver(I) carbonate.

As a rationalisation, it was proposed the mechanistic picture illustrated in the Scheme 2. Due to the well-known ability of the silver ion to facilitate the heterolysis of the carbon-halogen bond, ${ }^{13}$ it was envisaged the initial formation of the nitrilium ion $\mathbf{A}$. This intermediate can then evolve following alternative pathways: (i) proton elimination to generate the nitrilimine intermediate $\mathbf{B}$, (ii) electrophilic attack to the $\pi$ bond of the alkenol 2 to form the new carbocation $\mathbf{C}$. The pinacol-type rearrangement of the latter ${ }^{14}$ gave the carbonyl derivatives $\mathbf{5}$, whose formation have no precedent in the base-promoted reactions of hydrazonoyl halides with alkenols. $^{15}$ 
<smiles>COC(=O)/C(Cl)=N/Nc1ccccc1C(C)=O</smiles>

1<smiles>[R]C=CC([R])O</smiles>

2<smiles>[R]C(O)C1C([R])C(C(C)=O)=NN1c1ccccc1C(=O)OC</smiles>

3<smiles>[R1]C(O)C1C(C(C)=O)=NN(c2ccccc2C(=O)OC)C1[R2]</smiles>

4<smiles>[R]C(=O)CCC(=NNc1ccccc1C(=O)OC)C(=O)OC</smiles>

5

\section{Scheme 1}<smiles>COC(=O)C#[N+]Nc1ccccc1C(=O)OCC(=O)OC</smiles>

A

(ii) 2<smiles>[R]C(O)[CH+]C([R2])/C(=N\Nc1ccccc1C(=O)OC)C(=O)OC</smiles>

B

3,4

\section{Scheme 2}

Open-chain products similar to $\mathbf{5}$ were also found in the silver(I) carbonate-promoted reaction between hydrazonoyl chlorides and homoallylic or homopropargylic alcohols, ${ }^{16}$ thus further supporting the above mechanistic picture. As a common drawback, however, it should be pointed out that cycloaddition yields were low and a number of side-products were always formed. Furthermore, the cycloadditions were not regioselective when $\mathrm{R}^{1}$ and $\mathrm{R}^{2}$ were other than hydrogens. This unappealing behaviour was avoided using trimethylsilyl homoallylethers $\mathbf{7 a}$ and 
7b as dipolarophiles in the presence of silver(I) acetate (Scheme 3). ${ }^{17}$ The major cycloadducts 8 and 9 were highly preferred, being the regioisomeric ratio between 90:10 and 92:8. Further removal of the trimethylsilyl group from the latter cycloadducts with TBAF gave unprotected 4(1-hydroxy)ethyl-4,5-dihydropyrazoles with good overall yield (59-65\%). Cyclopropane derivatives $\mathbf{1 0}$ are unusual products whose formation can be ascribed to the multi-step ionic mechanism depicted in the Scheme 3. Electrophilic attack from the nitrilium-like ion to the $\mathrm{C}=\mathrm{C}$ double bond of 7 gave the new carbocation D. Proton loss from the latter intermediate and subsequent ring closure gave cyclopropane derivatives $\mathbf{1 0 .}$

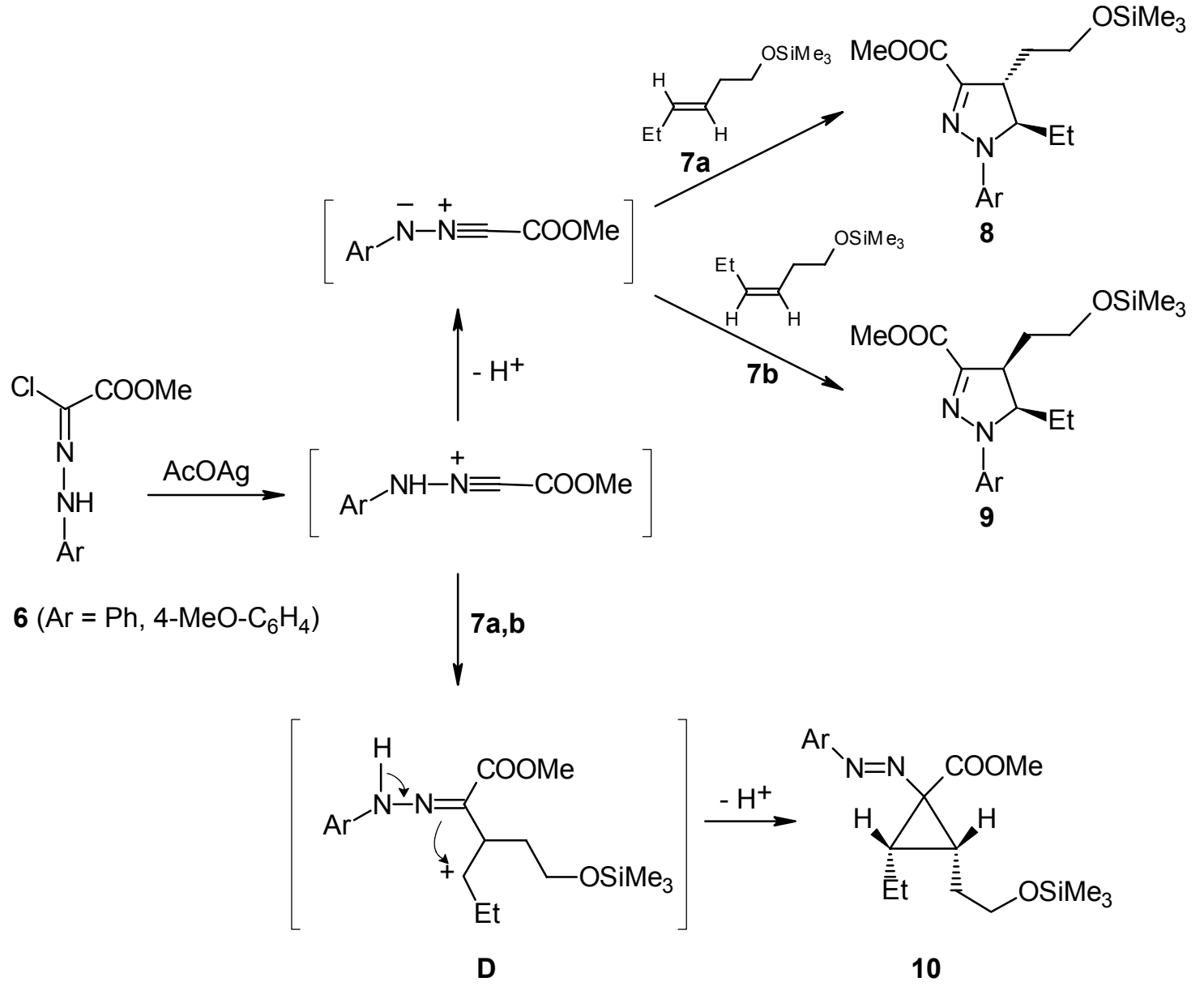

\section{Scheme 3}

The use of silver(I) carbonate as an unconventional basic agent has been exploited in the cycloaddition between nitrilimines and (arylsulfonyl)allene 11 (Scheme 4). ${ }^{18}$ The choice of silver(I) carbonate in the place of more common organic bases, like triethylamine ${ }^{19,20}$ comes from the following considerations: $(i)$ the allene $\rightarrow$ acetylene isomerisation is suppressed in the current reaction conditions; (ii) room temperature and heterogeneous reaction medium allow a smooth generation of the nitrilimine, so minimising the degradative processes of the 1,3-dipole. From a mechanistic standpoint, it is likely that the final pyrazoles $\mathbf{1 2}$ and $\mathbf{1 3}$ would originate 
from the first-formed cycloadducts $\mathbf{E}$ and $\mathbf{F}$, respectively, via 1,3-prototropic shift. ${ }^{19,21}$ The formation of the sulfinic ester intermediates $\mathbf{1 4}$ can be rationalised by invoking a $[2,3]$ sigmatropic rearrangement of cycloadduct $\mathbf{G}$ via a sulfur-to-oxygen bond migration. ${ }^{22}$ It needs to be added that, due to the HOMO-nitrilimine control of the cycloaddition, electron-rich nitrilimines (entries a-c,f) gave better results, while the cycloaddition pathway appeared impervious with electron-poor nitrilimines (entries d,e). The computational aspects of this reaction have been investigated by means of DFT reactivity indices. ${ }^{23}$

Nitrilimine cycloadditions to partially saturated heterocycles as (hetero)dipolarophiles are attractive reactions since it is possible to synthesise complex tri-, tetra- and pentacyclic heterocycles which are not easy to obtain by other routes.

The $\mathrm{C}=\mathrm{N}$ bond of the furo[3,4-c]pyrazoline $\mathbf{1 6}$ is able to react with hydrazonoyl chlorides in the presence of both silver(I) carbonate or silver(I) acetate giving the tricyclic compounds $\mathbf{1 7}$ with $2-32 \%$ yield (Scheme 5). ${ }^{24}$ The better results were obtained with silver(I) acetate, since some amount of the oxidation product $\mathbf{1 8}$ was always formed in the presence of silver(I) carbonate. This behaviour is not surprising in the light of the known oxidising ability of silver(I) carbonate. $^{25}$ Notwithstanding these low cycloaddition yields, it has to be underlined that by performing the above reactions in the presence of triethylamine no noticeable reaction occurred onto the $\mathrm{C}=\mathrm{N}$ bond of $\mathbf{1 6}$. 


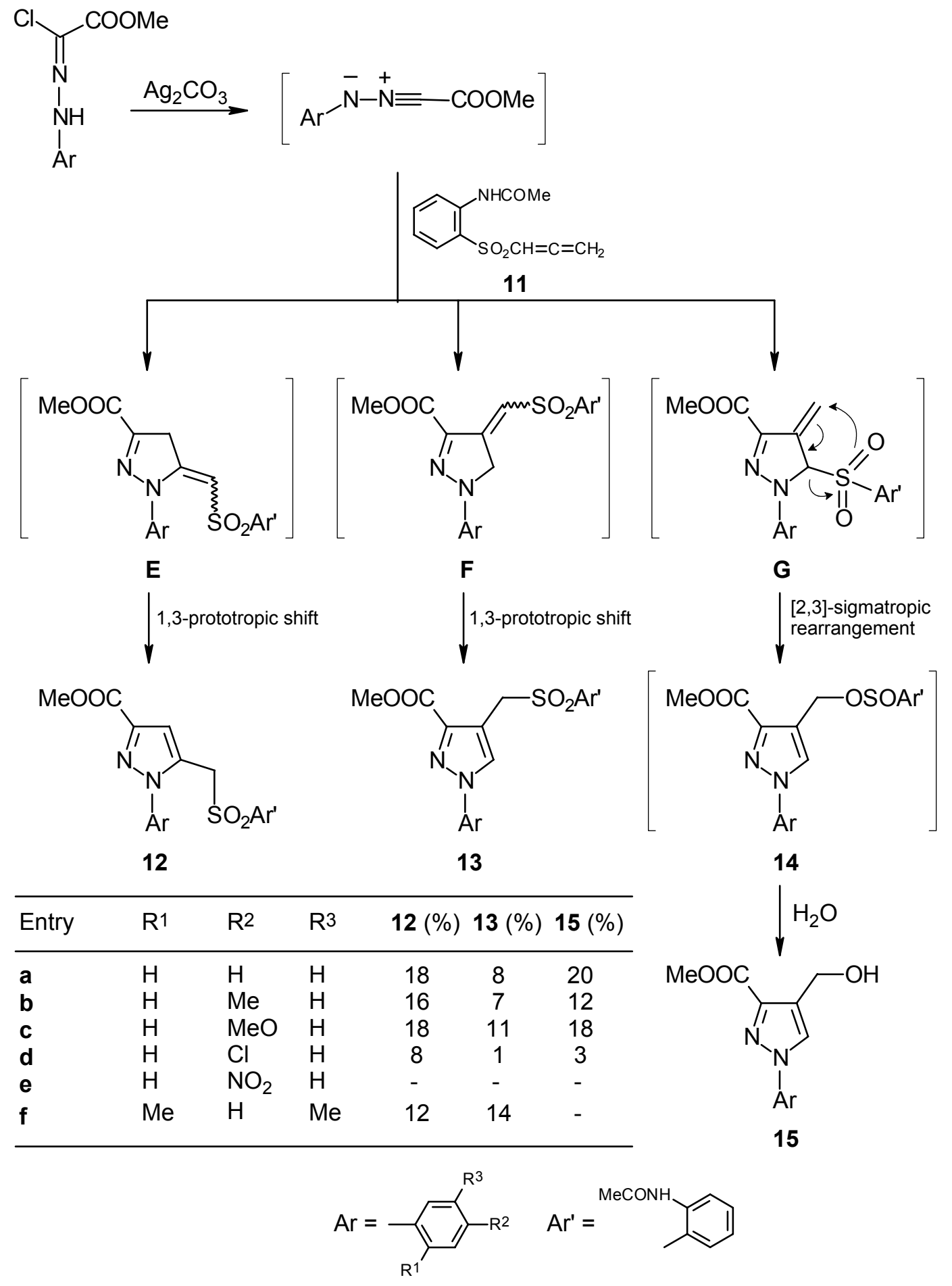

\section{Scheme 4}




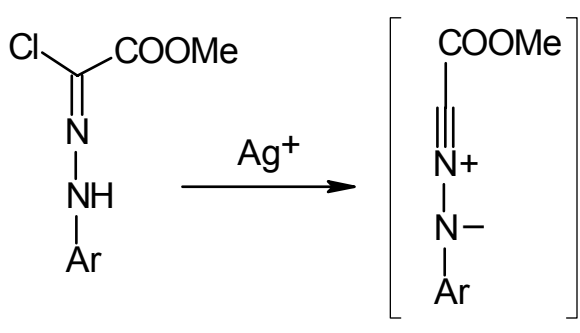

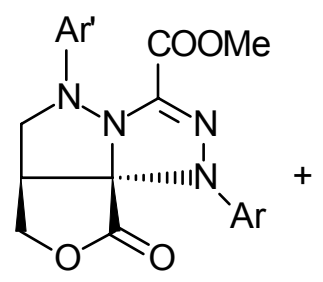

17<smiles>O=C1OCc2cn([Al])nc21</smiles>

18

$$
\begin{aligned}
& \mathrm{Ar}=4-\mathrm{Me}^{-} \mathrm{C}_{6} \mathrm{H}_{4}, 4-\mathrm{NO}_{2}-\mathrm{C}_{6} \mathrm{H}_{4} \\
& \mathrm{Ar} r^{\prime}=4-\mathrm{NO}_{2}-\mathrm{C}_{6} \mathrm{H}_{4}
\end{aligned}
$$

\section{Scheme 5}

Complex heterocycles have been obtained from partially saturated furo[3,4-c]thieno [2,3d]pyrazoles 19 (Scheme 6) ${ }^{26}$ The competitive formation of products due to the nitrilimine attack at different dipolarophilic sites has been observed, and the experimental evidence was discussed by taking into account electronic features of the reactive species as well as their steric encumbrance.
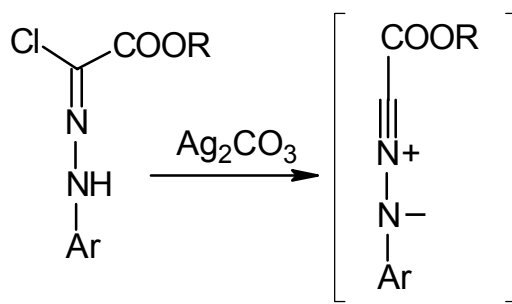

$\mathrm{R}=\mathrm{Me}, \mathrm{Bn}$

$\mathrm{Ar}=4-\mathrm{Me}-\mathrm{C}_{6} \mathrm{H}_{4}, 4-\mathrm{Cl}-\mathrm{C}_{6} \mathrm{H}_{4}, 4-\mathrm{NO}_{2}-\mathrm{C}_{6} \mathrm{H}_{4}$

$\mathrm{Ar}=\mathrm{Ph}, 4-\mathrm{Me}-\mathrm{C}_{6} \mathrm{H}_{4}, 4-\mathrm{Cl}-\mathrm{C}_{6} \mathrm{H}_{4}, 4-\mathrm{NO}_{2}-\mathrm{C}_{6} \mathrm{H}_{4}$
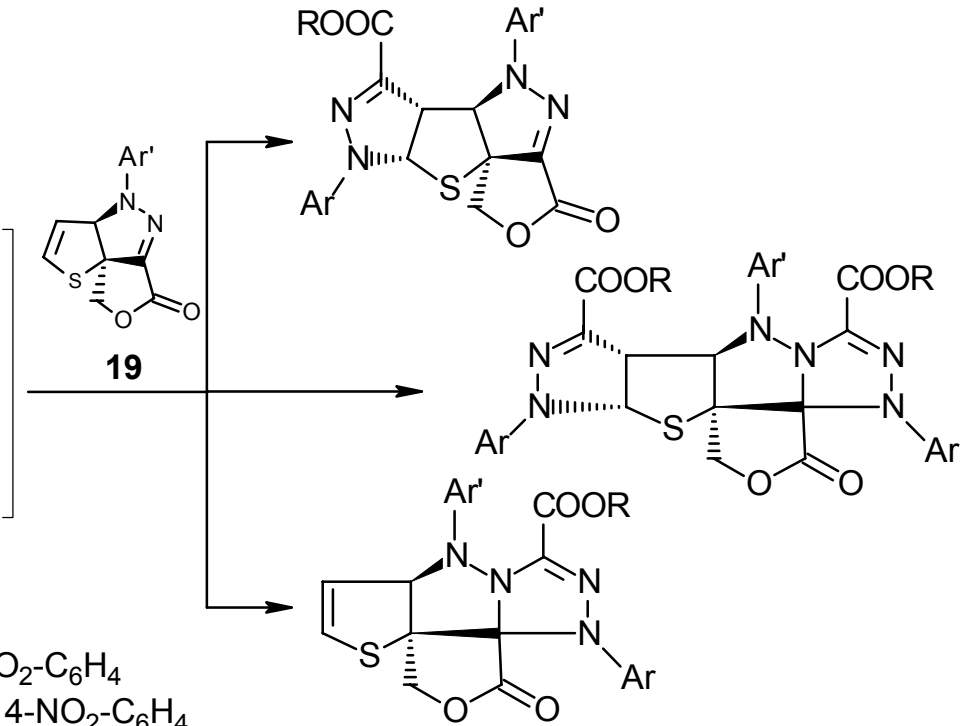

\section{Scheme 6}

Since the known antibiotic activity of 2-azetidinone-based heterocycles ${ }^{27}$ and the anti inflammatory features of some pyrazolines ${ }^{28}$ some compounds which brings together these heterocyclic fragments have been synthesised. The key step was an efficient nitrilimine cycloaddition to racemic 2-azetidinones $\mathbf{2 0}$ and $\mathbf{2 1}$ promoted by silver(I) acetate. Although not regioselective (regioisomeric ratio between 80:20 and 83:17), the cycloaddition to compound 20 
was fully stereoselective, ${ }^{29}$ while from the conjugated 2-azetidinone $\mathbf{2 1}$ was obtained a complex mixture of regio- and stereoisomers. ${ }^{30}$

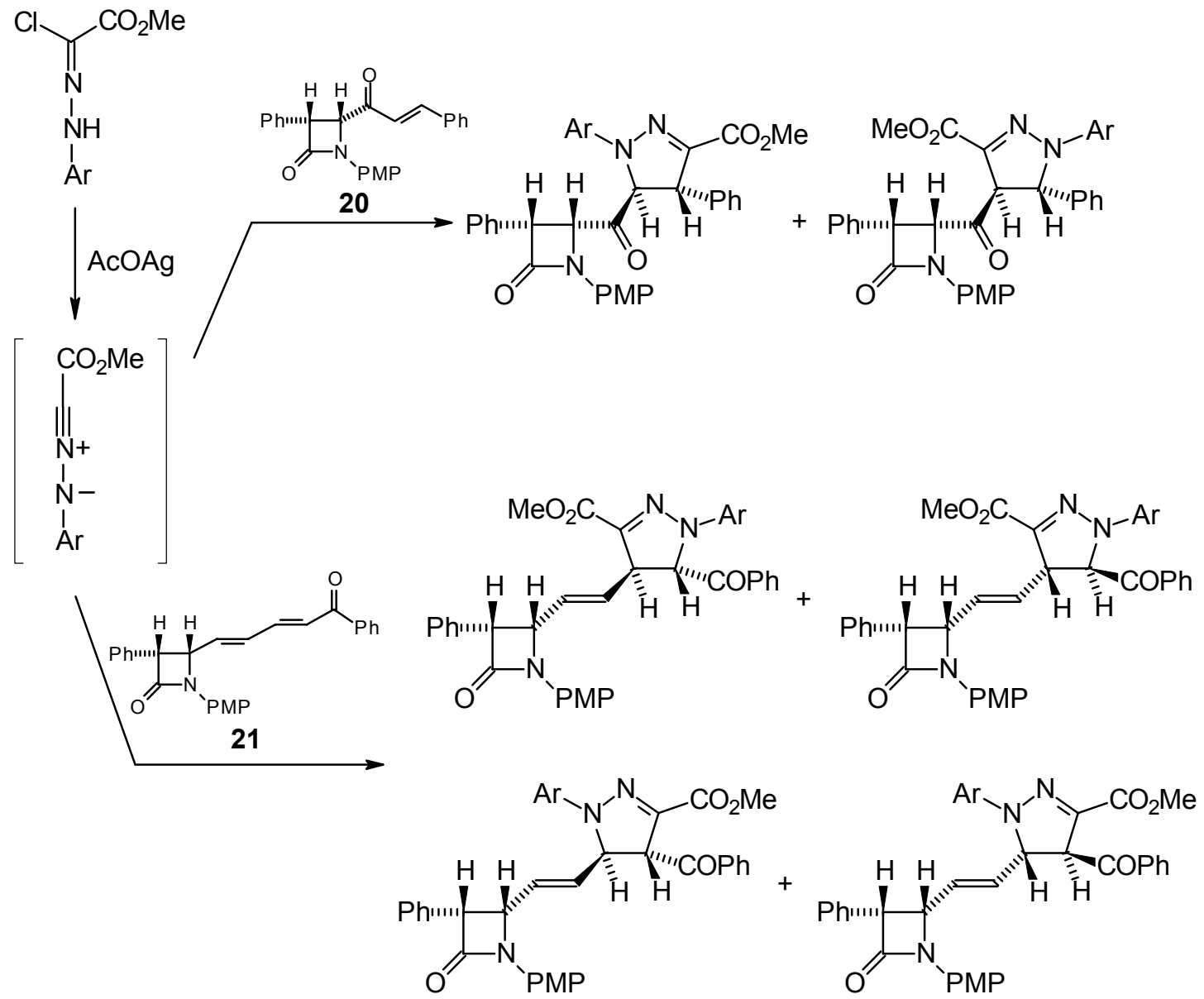

$\mathrm{Ar}=4-\mathrm{Me}-\mathrm{C}_{6} \mathrm{H}_{4}, 4-\mathrm{Br}-\mathrm{C}_{6} \mathrm{H}_{4} ; \mathrm{PMP}=4-\mathrm{MeO}-\mathrm{C}_{6} \mathrm{H}_{4}$

\section{Scheme 7}

\section{Intramolecular cycloadditions}

The most prominent features of intramolecular 1,3-dipolar cycloadditions ${ }^{31}$ are related to the linkage between the reacting groups, which allows the simultaneous formation of two annulated (or fused) rings. Furthermore, the entropic advantage due to intramolecularity ${ }^{32}$ works to improve the reactivity of the dipolarophilic fragment.

As far as intramolecular nitrilimine cycloadditions are concerned, the effect of the basic species used to generate these intermediates plays a key role in the whole process. The presence of triethylamine or very strong bases (e.g. sodium hydride) often cause the fast and irreversible generation of the nitrilimine which can force intermolecular processes leading to resinous 
materials. The effectiveness of silver(I) salts in a heterogeneous medium is the consequence of the very slow generation of the nitrilimine intermediate, which mimics high-dilution conditions favouring intramolecular over intermolecular pathways.

The following sections will be illustrated according to the length of the tether joining the reactive groups, i.e. to the size of the ring to which the pyrazole nucleus is annulated.

\subsection{Formation of pyrazoles annulated to a five- or six- membered ring}

Acetylenic $\alpha$-diazoketones 22 bearing gem-dimethyl substituents in the $\alpha$ '-position were capable to undergo intramolecular cycloaddition in the presence of silver(I) carbonate or silver(I) oxide giving the corresponding bicyclic pyrazoles (Scheme 8). ${ }^{33}$ This behaviour was somewhat surprising since no trace of the expected Wolff rearrangement product was observed. However, bicyclic pyrazole derivatives were isolated with 35 to $55 \%$ yields depending on the silver(I) salt only in the presence of the mentioned gem-dimethyl substitution, which finds a rationale in terms of steric effects on conformational energies in the transition state.

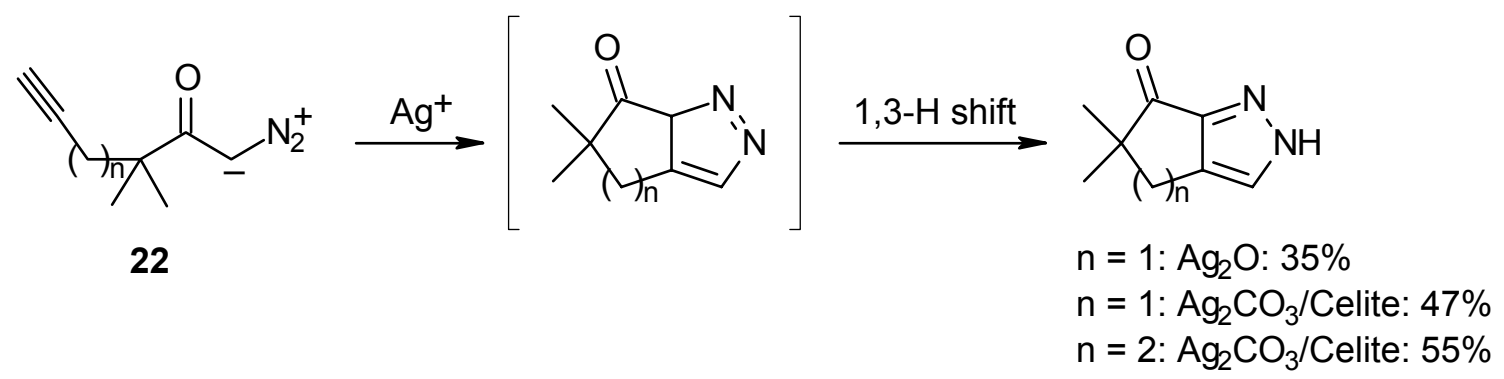

\section{Scheme 8}

Despite their propensity for substitution rather than addition reactions, various fivemembered heteroaromatics can behave as dipolarophiles in intramolecular cycloadditions of 1,3dipoles. ${ }^{34}$ Plausibly, the high energy barrier due to the loss of aromaticity is overcome by favourable entropic contributions working in intramolecular reactions. ${ }^{32}$ Intramolecular nitrilimine cycloaddition onto a thiophene, ${ }^{35}$ furan, ${ }^{36}$ and isoxazole ${ }^{37}$ ring (Scheme 9) were described as a synthetic route to a number of tricyclic pyrazoline derivatives. All these cycloadditions work well only in the presence of silver(I) salts, while the use of triethylamine as the base did not produce any appreciable reaction. In the case of the thiophene and isoxazole dipolarophiles the formation of diadducts $\mathbf{2 4 ,} 25$ and 27 can be ascribed to a sequential intraintermolecular cycloaddition pathway. 

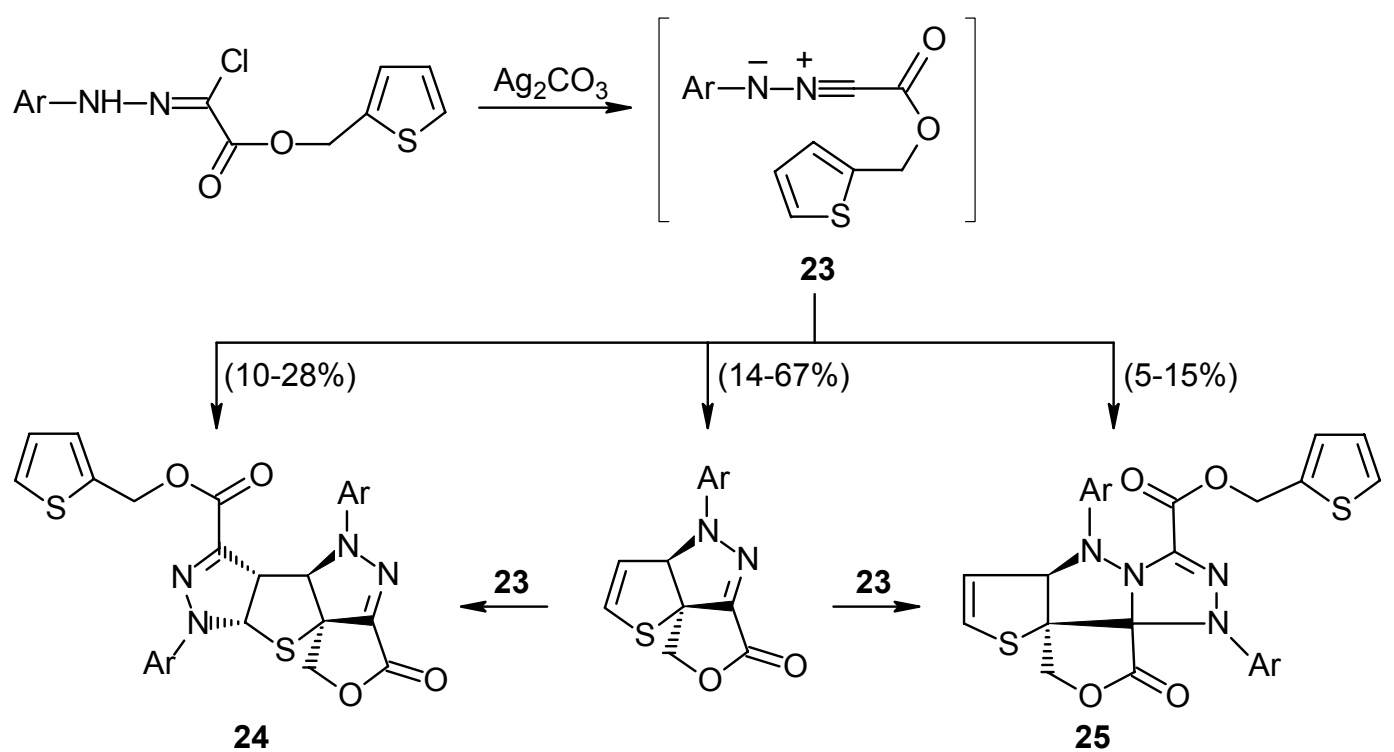

$\mathrm{Ar}=\longrightarrow \mathrm{R}=\mathrm{H}, \mathrm{Me}, \mathrm{MeO}, \mathrm{F}, \mathrm{Cl}, \mathrm{COMe}, \mathrm{NO}_{2}$
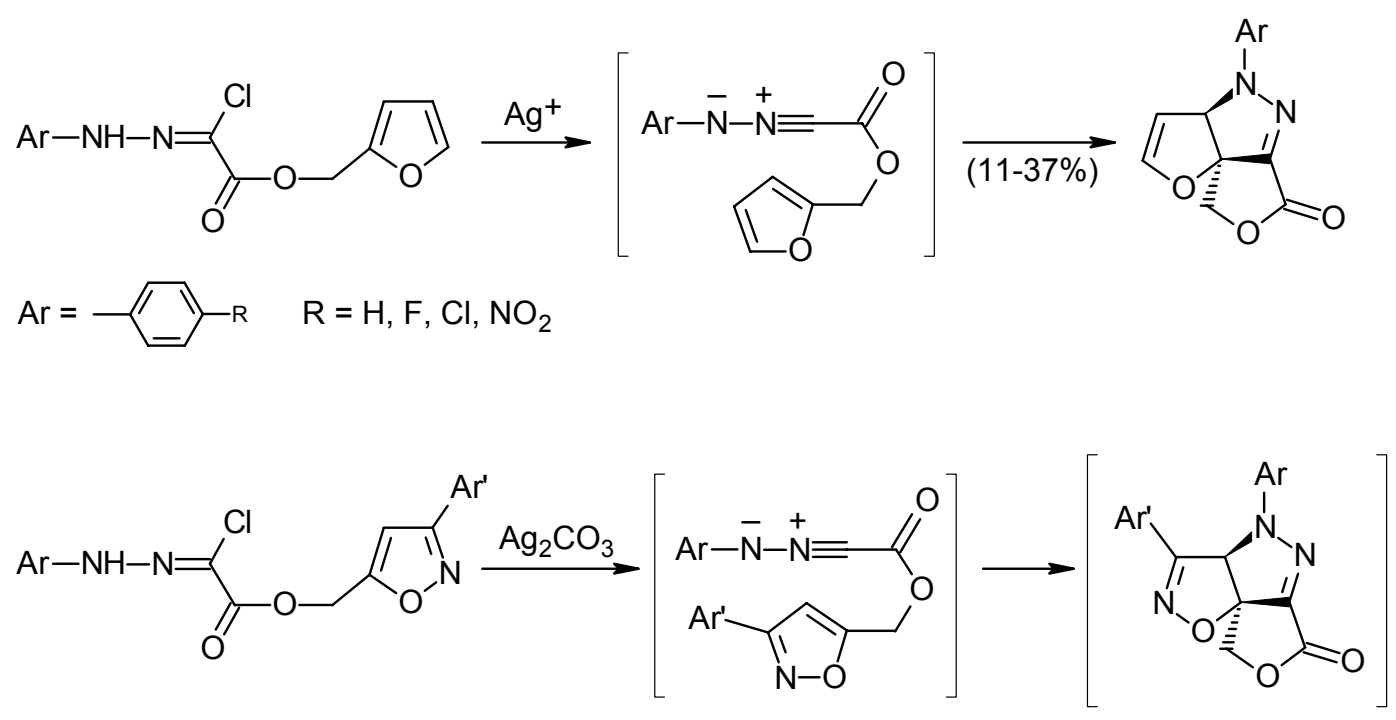

26

$$
\mathrm{Ar}^{\prime}=
$$

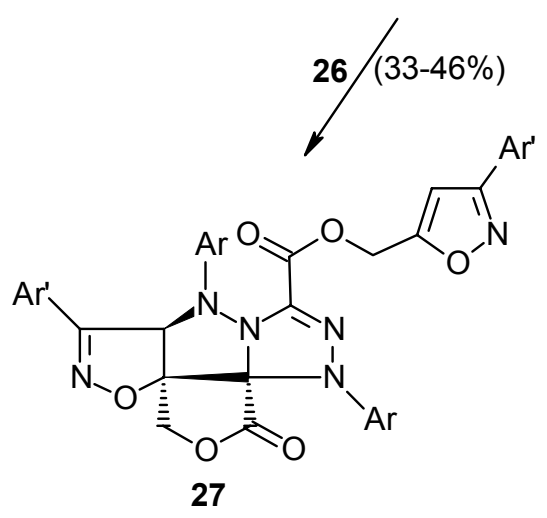

\section{Scheme 9}


The examples described above involve intramolecular reactions in which the dipolarophile is linked to the $C$ terminus of the 1,3-dipole. Only one recent report deals with the behaviour of $N$ substituted nitrilimines in which the thiophene ring acts as the dipolarophile (Scheme 10). ${ }^{38}$ The formation of the cycloadduct $\mathbf{2 8}$ have been rationalised on the basis of the corresponding transition state optimised at the B3LYP/cc-pVDZ level.

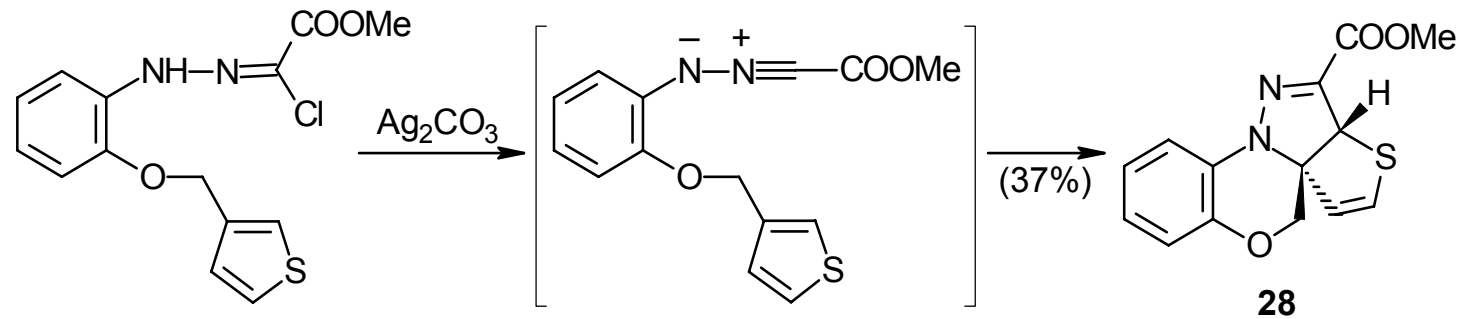

\section{Scheme 10}

\subsection{Formation of pyrazoles annulated to a medium-sized ring}

Pyrazoles annulated with a seven-, ${ }^{39}$ eight- ${ }^{39}$ nine- ${ }^{40,41}$ and ten- ${ }^{40,41}$ membered ring have been synthesised by nitrilimine cycloaddition onto a terminal $\mathrm{C} \equiv \mathrm{C}$ bond in the presence of silver(I) carbonate (Scheme 11). Partially unsaturated analogues of the latter cycloadducts have been obtained under the same reaction conditions from the corresponding hydrazonoyl chlorides bearing an ethylenic dipolarophile. ${ }^{42,43}$ For the sake of comparison, some of the starting hydrazonoyl chlorides were found very slow to react with triethylamine or similar bases even in more severe conditions. ${ }^{44}$

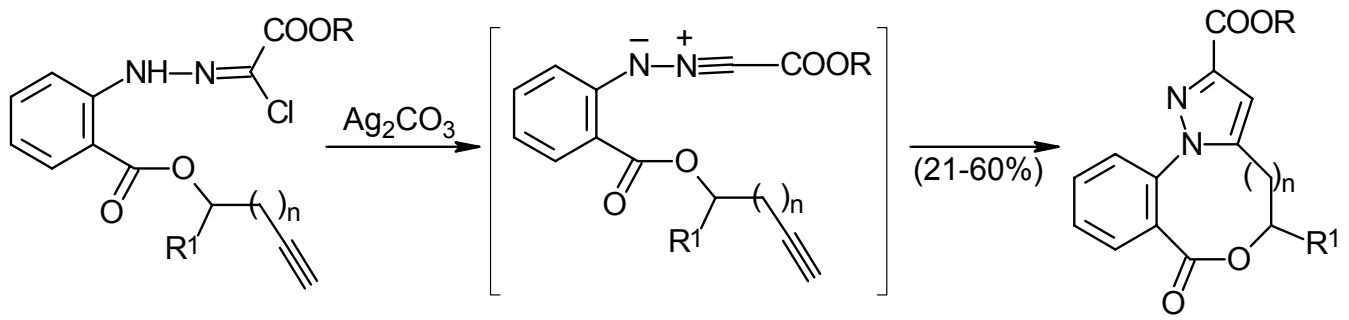
$n=0,1,2,3 ; R=M e, E t ; R^{1}=H, M e, P h$

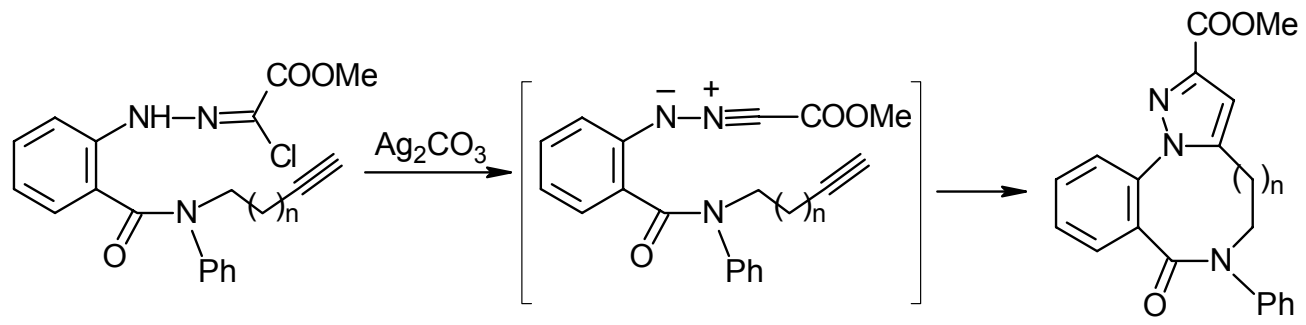
$n=2: 47 \% ; n=3: 43 \%$

\section{Scheme 11}




\subsection{Formation of pyrazoles annulated to a large-sized ring}

A number of strategies have been devoted to the synthesis of macrocyclic systems, including that based upon a multiple 1,3-dipolar cycloaddition sequence. This latter approach has been pioniered by Garanti and co-workers in a 1975 paper which describes the formation of macrocyclic compounds using intermolecular followed by intramolecular cycloadditions of nitrile oxides bearing an alkenyl dipolarophile. ${ }^{45}$ The synthesis of a variety of $(1,5)$ pyrazolophanes ${ }^{42,43,46}$ can be accomplished by treating a suitably functionalised hydrazonoyl chloride with silver(I) carbonate (Schemes 12 and 13). Of course, the intermolecular plus intramolecular cycloaddition sequence is competitive with the direct intramolecular cycloaddition, and the predominance of one pathway over the other is dependent on the length and the rotational freedom of the tether joining the reactive groups.

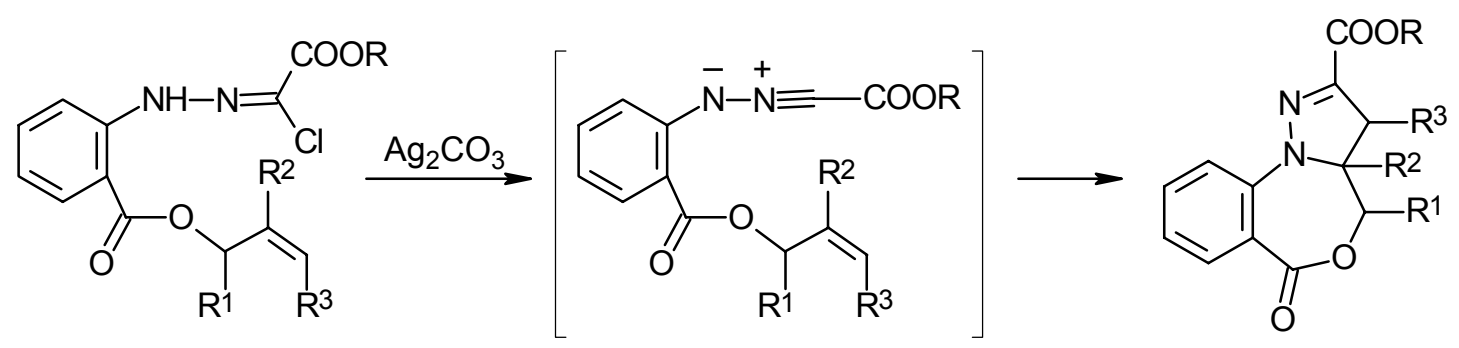

29
30<smiles>[R]OC(=O)C1=NN(c2ccccc2C(=O)OCC2([R2])CC(C(=O)O[R])=NN2c2ccccc2C(=O)OCC)C([R])(COC(=O)[O-])C1</smiles>

31<smiles>CCOC(=O)C1=NN(c2ccccc2C(=O)OCC)[C@H](C(C)OC(=O)c2ccccc2N2N=C(C(=O)OCC)C[C@H]2C)C1</smiles>

32<smiles>[M]C1[C@H](COC(=O)c2ccccc2N2N=C(C(=O)OCC)[C@H](COC(=O)OCC)C2[M])C(C(=O)OCC)=CN1c1ccccc1</smiles>

33

$$
\begin{array}{llllllll}
\hline \text { Entry } & \mathrm{R} 1 & \mathrm{R} 2 & \mathrm{R} 3 & \mathbf{3 0}(\%) & \mathbf{3 1}(\%) & \mathbf{3 2}(\%) & \mathbf{3 3}(\%)
\end{array}
$$

\begin{tabular}{llllllll}
\hline a & $\mathrm{H}$ & $\mathrm{H}$ & $\mathrm{H}$ & 18 & 14 & - & - \\
$\mathbf{b}$ & $\mathrm{H}$ & $\mathrm{Me}$ & $\mathrm{H}$ & 14 & 16 & - & - \\
$\mathbf{c}$ & $\mathrm{H}$ & $\mathrm{H}$ & $\mathrm{Me}$ & - & - & 12 & - \\
d & $\mathrm{Me}$ & $\mathrm{H}$ & $\mathrm{H}$ & 28 & - & - & 8 \\
\hline
\end{tabular}

\section{Scheme 12}



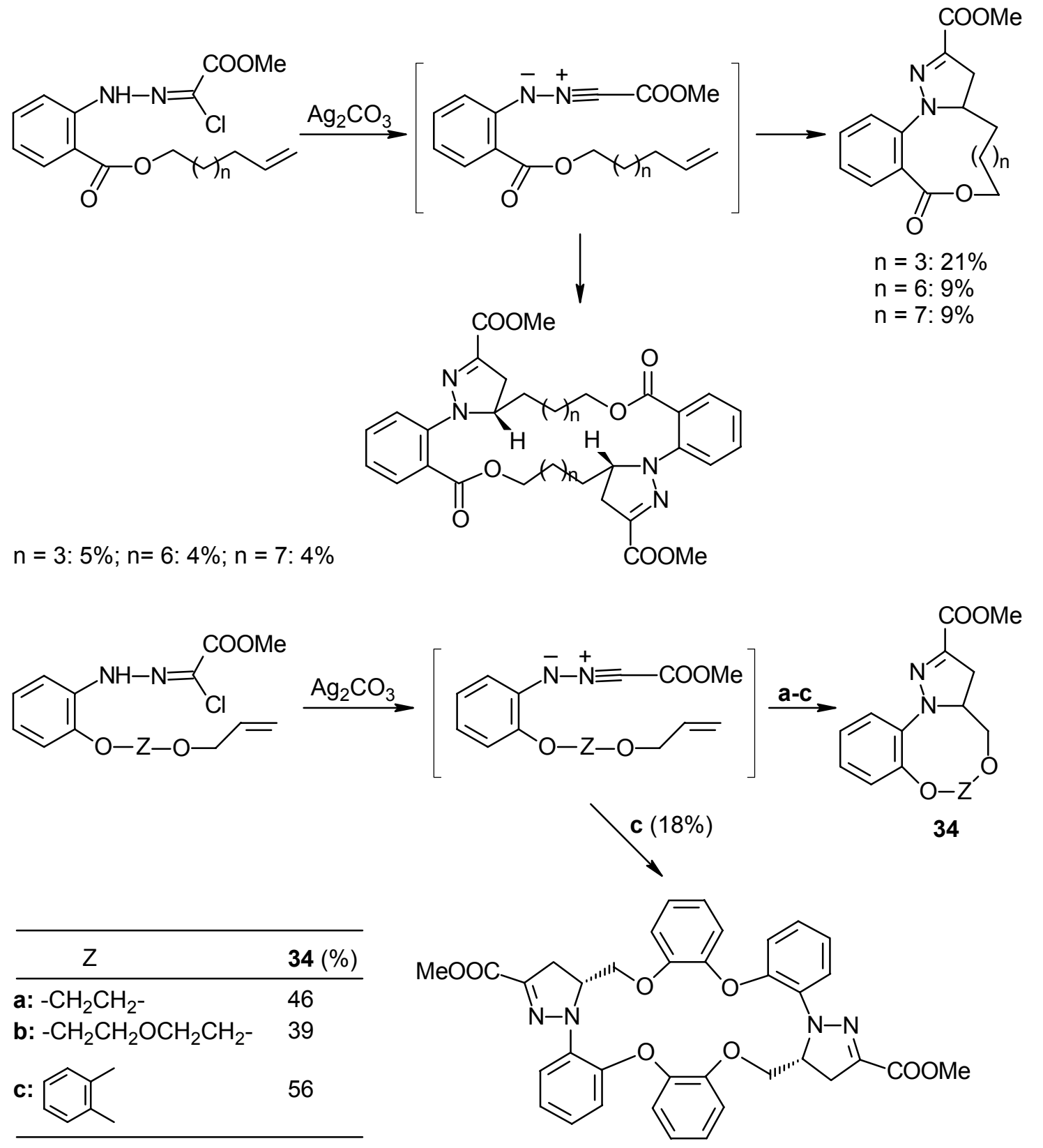

\section{Scheme 13}

Here again, the presence of a common base like triethylamine did not produce any appreciable result since large amounts of tarry material were usually formed. The intermolecularintramolecular cycloadditive protocol promoted by silver(I) carbonate was also applied to $C$ substituted nitrilimines as precursors of bis- $(3,5)$ pyrazolophanes. ${ }^{47}$

Following the multiple cycloadditive macrocyclisation between bis-nitrile oxides and bifunctional dipolarophiles introduced by Kim and co-workers, ${ }^{48}$ it was reported a version of the same methodology based upon the double cycloaddition between bis-hydrazonoyl chlorides and 
bis-dipolarophiles in the presence of silver carbonate as the basic agent (Scheme 14). ${ }^{49}$ Macrocyclic products $\mathbf{3 5}$ and $\mathbf{3 6}$ were obtained with good combined yields (36-59\%).

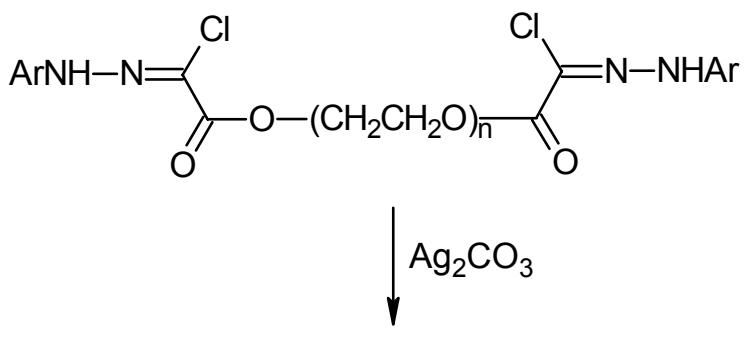<smiles>C=CCOCCOCCCOC(=O)C(Cl)=NN[Te]</smiles><smiles>C=CCOCCOCC1CC(C(=O)OCCOC(=O)C#[N+]N(C)[Ga])=NN1[Ga]</smiles>

\begin{tabular}{lccc}
\hline $\mathrm{Ar}$ & $\mathrm{n}$ & $\mathbf{3 5}(\%)$ & $\mathbf{3 6}(\%)$ \\
\hline $4-\mathrm{Cl}-\mathrm{C}_{6} \mathrm{H}_{4}$ & 1 & 24 & 12 \\
$4-\mathrm{Cl}_{6} \mathrm{C}_{6} \mathrm{H}_{4}$ & 2 & 26 & 17 \\
$4-\mathrm{Me}-\mathrm{C}_{6} \mathrm{H}_{4}$ & 1 & 31 & 16 \\
$4-\mathrm{Me}-\mathrm{C}_{6} \mathrm{H}_{4}$ & 2 & 40 & 19 \\
\hline
\end{tabular}

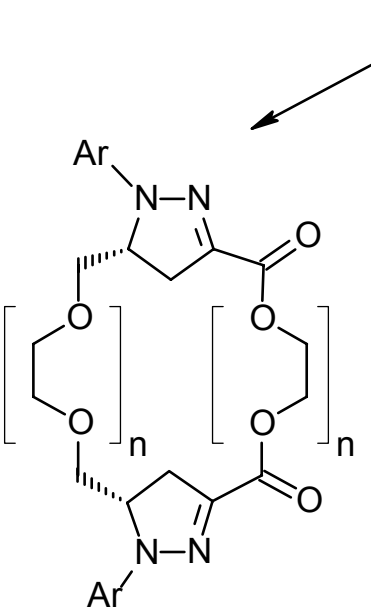

35

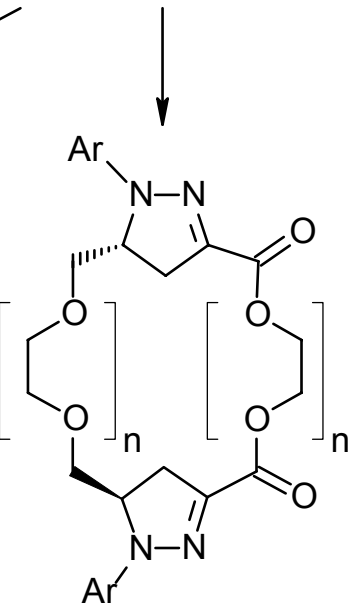

36

\section{Scheme 14}

\section{Stereoselective cycloadditions}

Due to the utility of enantiopure pyrazolines in organic synthesis and some interesting applications of related products, stereoselective cycloadditions of nitrilimines have become useful in the last few years, and the subject have been recently reviewed. ${ }^{50}$ Much of the examples discussed above actually involves stereoselective cycloadditions, although onto racemic 
substrates. The aim of this paragraph is to present the behaviour of silver(I) salts-promoted nitrilimine cycloadditions towards stereoselectivity in the synthesis of enantiopure heterocycles. For this reason the discussion will be restricted to cover cycloadditions in which the product(s) is optically active.

\subsection{Intermolecular stereoselective cycloadditions}

A variety of naturally-occurring pinane derivatives, namely $(S)$-cis-verbenol 37, (1R)-(-)myrtenol 38, (1S)-(-)-verbenone 39 and (1R)-(-)-myrtenal 40 have been submitted to nitrilimine cycloaddition in the presence of both triethylamine and silver(I) salts (Scheme 15). ${ }^{51}$ Due to the severe steric hindrance exerted by the two methyl groups placed onto the cyclobutyl ring of the dipolarophiles, these processes resulted fully stereoselective irrespective to the basic agent.

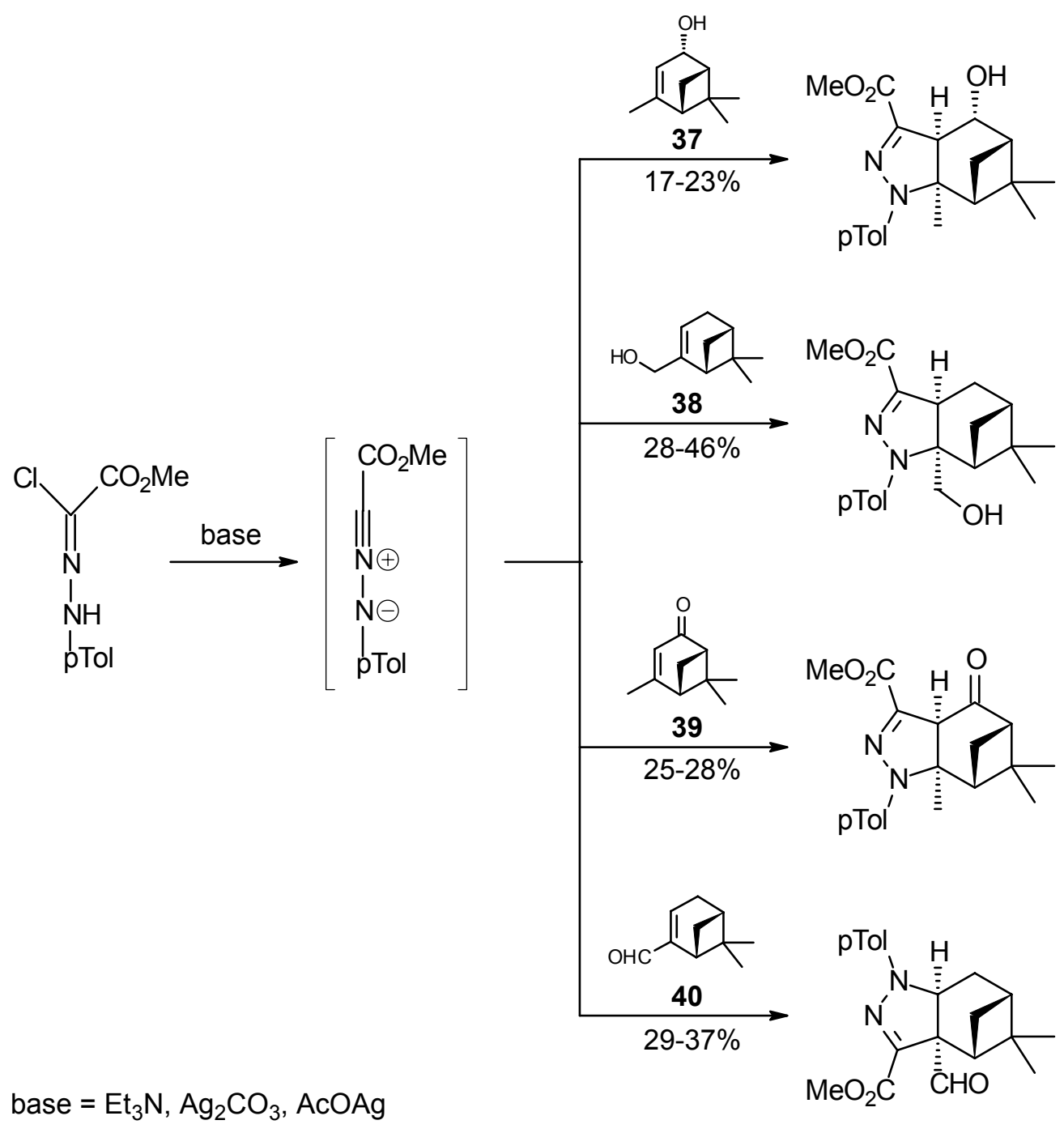

\section{Scheme 15}


In contrast to the above examples, nitrilimine cycloadditions to limonene derivatives (1S)-(-)perillyl alcohol and (S)-(-)-perillaldehyde resulted as site- and regioselective but not stereoselective processes. 51

The behaviour of nitrilimines towards a series of enantiopure acrylamides $\mathbf{4 1}$ was investigated in the presence of several basic agents, namely triethylamine, (-)-sparteine and silver(I) acetate $^{52}$ (Scheme 16). The diastereoisomeric ratio ranges between 58:42 and 83:17 depending upon the chiral auxiliary connected to the $\alpha, \beta$-unsaturated dipolarophile. The best results, obtained with acrylamides 41c and 41e, possibly reflect the lower conformational flexibility of the latter two substrates compared to 41a, 41b and 41d. The base and the presence of salts as $\mathrm{LiCl}$ and $(\mathrm{AcO})_{2} \mathrm{Mg}$, which were investigated as potential complexating agents, exerted little or no influence on cycloaddition diastereoselectivity.

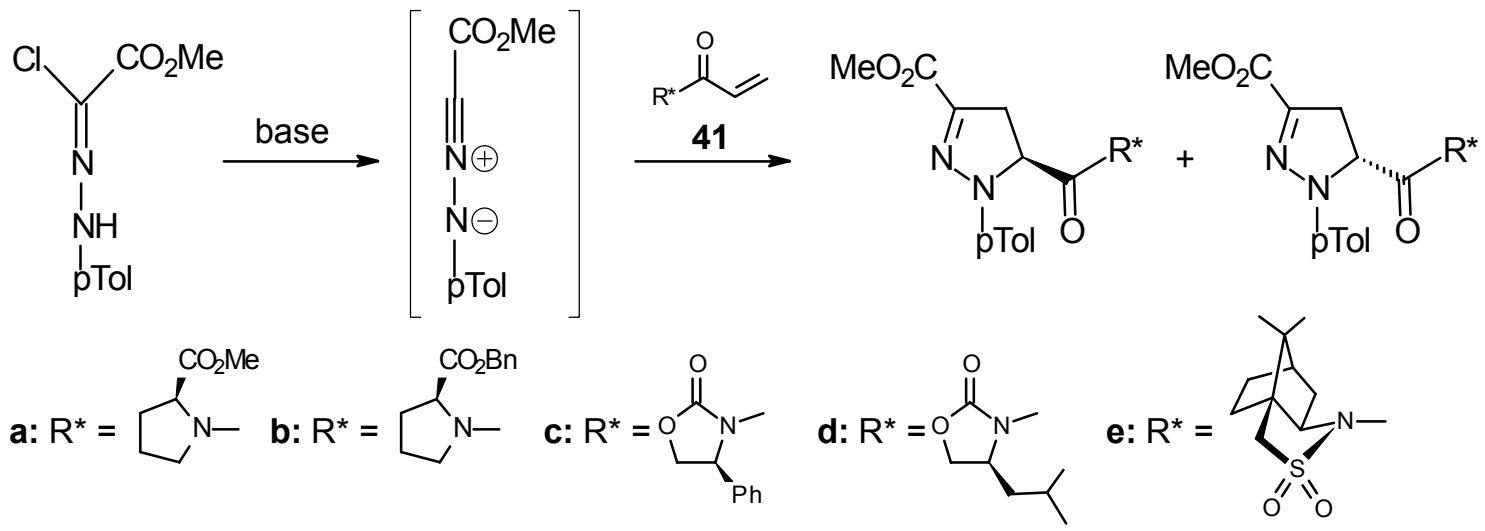

\section{Scheme 16}

\subsection{Intramolecular stereoselective cycloadditions}

Due to their versatility, intramolecular nitrilimine cycloadditions constitute a powerful approach to a wide range of heterocyclic systems. ${ }^{53}$ Furthermore, the products arising from these processes are generally complex polycyclic, annulated, and fused ring heterocycles that are difficult to prepare by any other method. From these preliminary remarks, it can be argued that a way which allows the synthesis of the mentioned products in the enantiopure form should be highly desirable.

As far as the synthesis of pyrazoles annulated to a five-membered ring is concerned, it may be recalled that the construction of the furo[3,4-c]pyrazole skeleton belongs to the first success of the intramolecular nitrilimine cycloaddition methodology. ${ }^{54}$ The first case of asymmetric induction in such reactions promoted by silver(I) carbonate was reported in $1999,{ }^{55}$ giving rise to a mixture of enantiopure cycloadducts 42 and 43 (Scheme 17). Since the intramolecular cycloaddition of nitrilimines 44 occurred with a lower degree of diastereoselectivity, ${ }^{56}$ it is 
apparent that better results are obtained if the pre-existing stereocentre is placed in the $\alpha$ position to the ethylenic dipolarophile or the 1,3-dipole (closer to the reaction site).

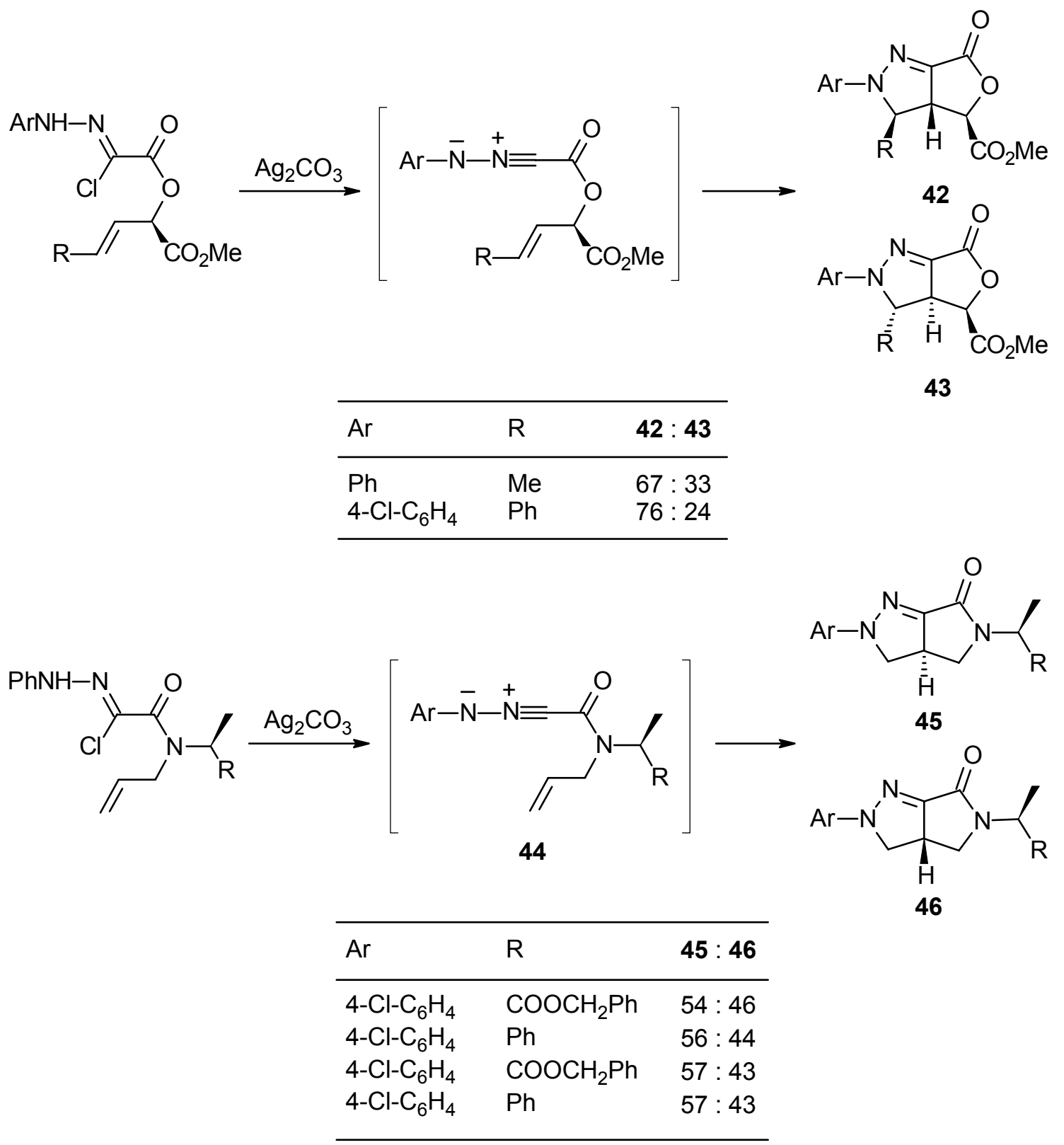

\section{Scheme 17}

A further example of pyrazoline annulated to a five-membered ring is given by the tricyclic $\beta$-lactam 47, which was obtained with full stereoselectivity. ${ }^{57}$ 


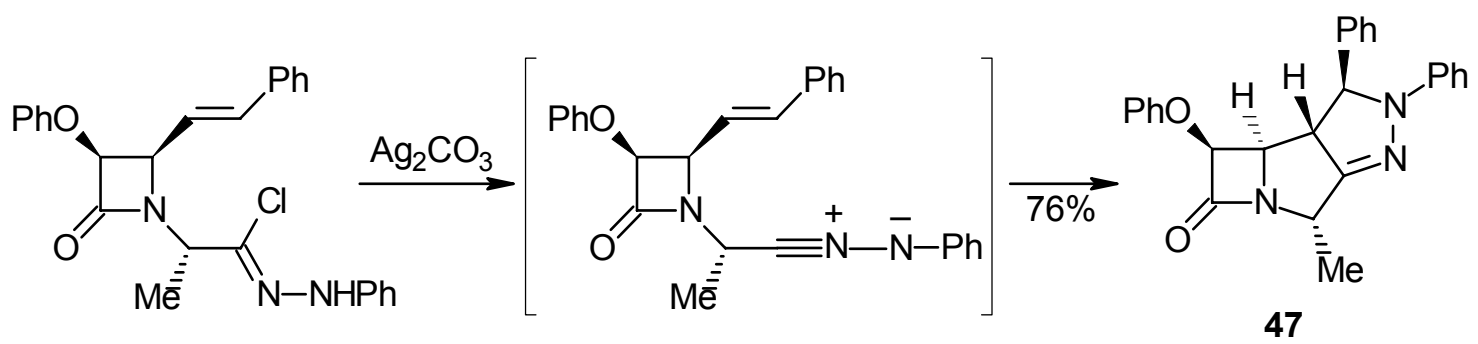

\section{Scheme 18}

Annulated [1,4]benzodiazepines represent valuable synthetic targets due to their well-known pharmacological activity as hypnotics and sedatives. ${ }^{58}$ Their stereoselective synthesis by silver(I) carbonate-promoted nitrilimine cycloaddition have been achieved with selectivities ranging from low (54:46) to good (80:20) in favour of the depicted enantiopure diastereoisomer (Scheme 19). ${ }^{59-61}$ Anyway, this stereochemical outcome is worth noting because the distance between the pre-existing and the newly-formed stereocentres is rather large.
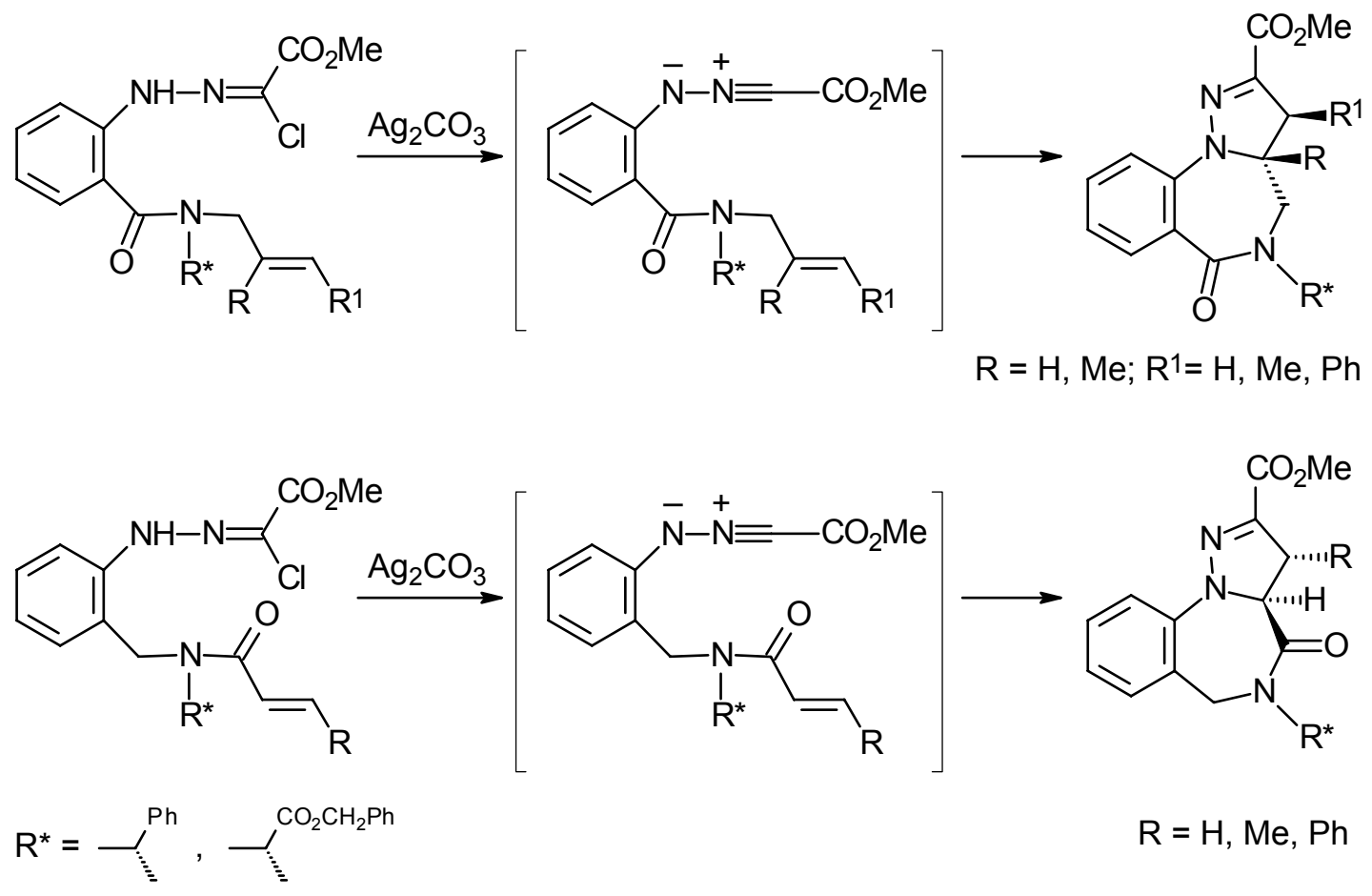

\section{Scheme 19}

The replacement of the 2-(S)-phenylethyl or the benzyl 2-(S)-propionate chiral auxiliaries with the $(1 R, 2 S, 5 R)-(-)$-menthyl one caused a drop of the cycloaddition stereoselectivity since no diastereoisomeric excesses were produced (Scheme 20). ${ }^{62}$ 


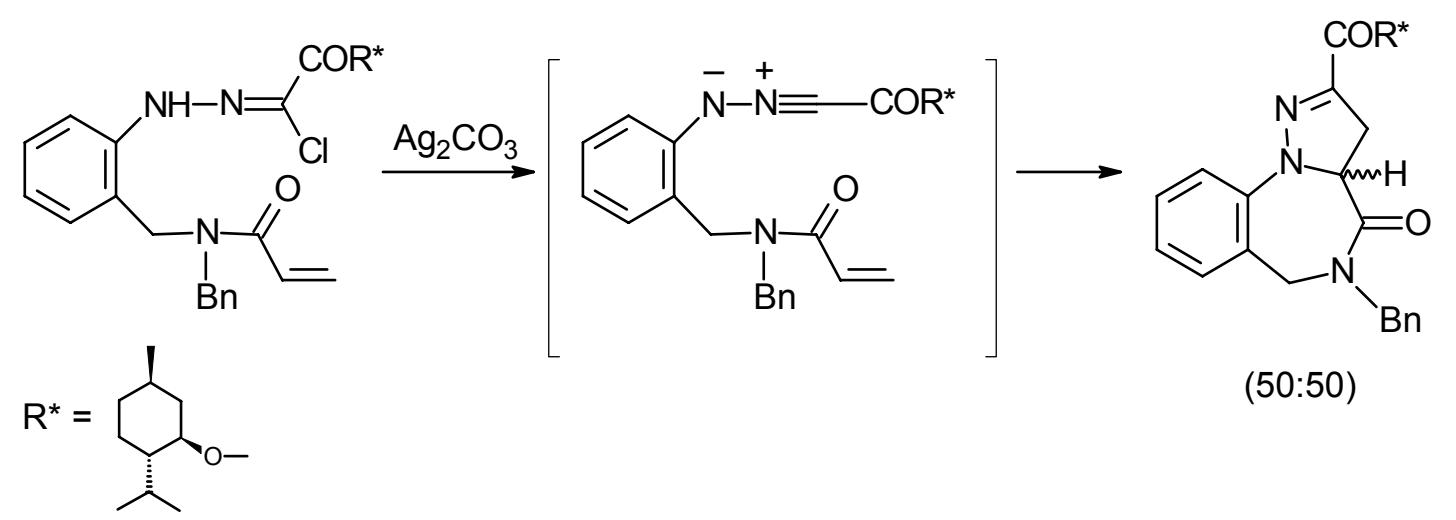

\section{Scheme 20}

The sequential inter- intramolecular cycloadditions of nitrilimine 49 (Schemes 21) gave the enantiopure pyrazolophane 50. ${ }^{63}$ This macrocyclic compound have been obtained as a single diastereoisomer, possibly due to the asymmetric induction of the pre-existing stereocentre reinforced by some kind of coordination between the silver ion and the ethereal oxygens of the reactants.

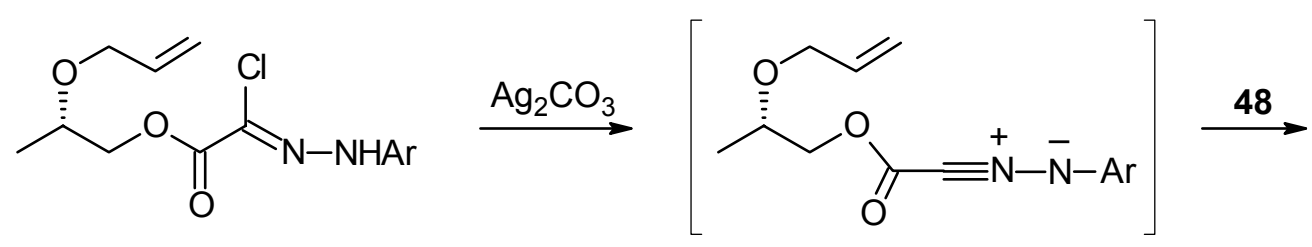

48

49

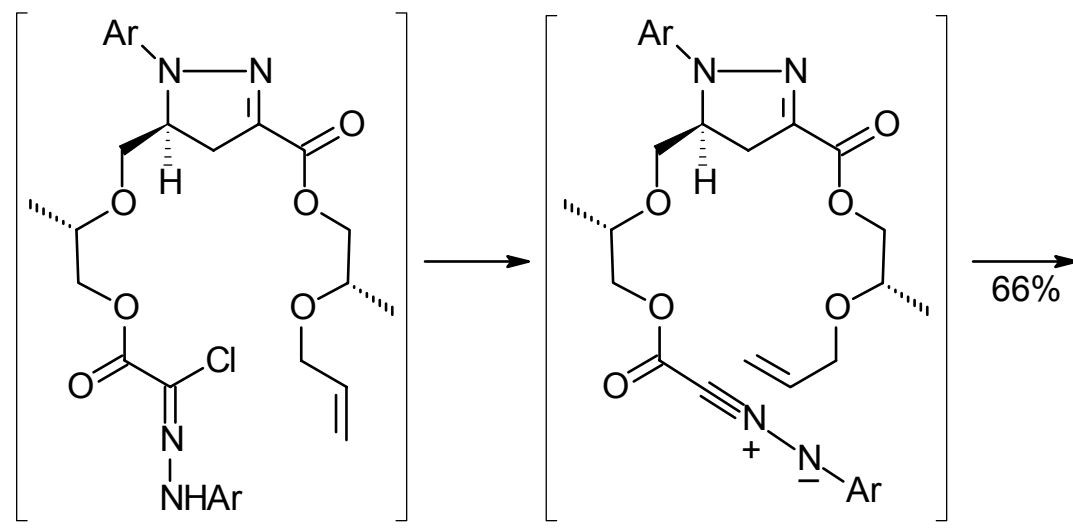

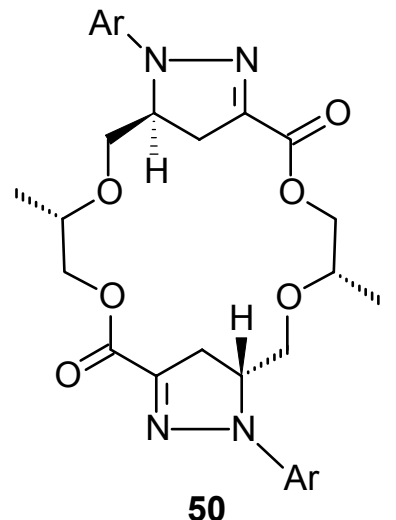

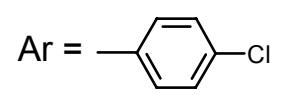

Scheme 30 


\section{Acknowledgements}

MURST (Rome) is gratefully acknowledged for financial support.

\section{References and Notes}

1. Elguero, J. In Comprehensive Heterocyclic Chemistry; Katritzky, A. R.; Rees, C. W. Eds.; Pergamon Press: Oxford, 1985, Vol. 5.

2. Elguero, J.; Goya, P.; Jagerovic, N.; Silva, A. M. S. Targets in Heterocycl. Syst. 2002, 6, 52.

3. Penning, T. D.; Talley, J. J.; Bertenshaw, S. R.; Carter, J. S.; Collins, P. W.; Docter, S.; Graneto, M. J.; Lee, L. F.; Malecha, J. W.; Miyashiro, J. M.; Rogers, R. S.; Rogier, D. J.; Yu, S. S.; Anderson, G. D.; Burton, E. G.; Cogburn, J. N.; Gregory, S. A.; Koboldt, C. M.; Perkins, W. E.; Seibert, K.; Veenhuizen, A. W.; Zhang, Y. Y.; Isakson, P. C. J. Med. Chem. 1997, 40, 1347.

4. Sainsbury, M.; Theobald, R. S. In Rodd's Chemistry of Carbon Compounds; Coffey, $\quad$ S.; Ansell, M. F. Eds.; Elsevier: Oxford, 1985, Vol. IVC, Ch. 16, pp 1.

5. (a) Wade, P. A. In Comprehensive Organic Synthesis; Trost, B.; Fleming I. Eds.; Pergamon Press: New York, 1992, Vol. 4, Ch. 4-10, p 1111. (b) Padwa, A. In Comprehensive Organic Synthesis; Trost, B.; Fleming I. Eds.; Pergamon Press: New York, 1992, Vol. 4, Ch. 4-9, p 1069. (c) Synthetic Applications of 1,3- Dipolar Cycloaddition Chemistry toward Heterocycles and Natural Products; Padwa, A.; Pearson, W. H. Eds.; Wiley: New York, 2002.

6. Wulfman, D. S.; Linstrumelle, G. In The Chemistry of Diazonium and Diazo Group; Patai, S. Ed.; John Wiley \& Sons: New York, 1978, Part 2, Ch. 18, pp 821.

7. Caramella, P.; and Grünanger, P. In: 1,3-Dipolar Cycloaddition Chemistry; Padwa, A. Ed.; Wiley-Interscience: New York, 1984, Vol. 1, Ch. 3.

8. Claus, P. K. In Methoden der Organische Chemie (Houben-Weil); Klamann, D.; Hagemann, H. Eds; Georg Thieme Verlag: Stuttgart, 1990, Band E14b, Teil 1, pp 33.

9. (a) Huisgen, R.; Seidel, M.; Wallbillich, G; Knupfer, H. Tetrahedron 1962, 17, 3. (b) Huisgen, R. Angew. Chem., Int. Ed. 1963, 2, 565 and 633. (c) Huisgen, R. Fliegl, $\quad$ W.; Kolbeck, W. Chem. Ber. 1983, 116, 3027.

10. (a) Padwa, A.; Nahm, S. J. Org. Chem. 1979, 44, 4746. (b) Padwa, A.; Nahm, S. J. Org. Chem. 1981, 46, 1402.

11. Garanti, G. Molteni, G. Zecchi Heterocycles 1994, 40, 777.

12. Huisgen, R.; Knupfer, H.; Sustmann, R.; Wallbillich, G.; Weberndörfer, V. Chem. Ber. 1967, $100,1580$.

13. 13. De La Mare, P. B. D.; Swedlund, B. E. In The Chemistry of the Carbon-Halogen Bond; Patai, S. Ed.; John Wiley \& Sons: London, 1973, Part 1, Ch. 7, pp 454.

14. Collins, C. J. Quart. Rev. 1960, 14, 357. 
15. (a) Bianchi, G.; De Micheli, C.; Gandolfi, R. In: The Chemistry of Double-Bonded Functional Groups; Patai, S. Ed.; John Wiley \& Sons: London, 1977, Part 1, Ch. 5, pp 421. (b) Shawali, A. S.; Párkáni, C. J. Heterocycl. Chem. 1980, 17, 833.

16. Broggini, G.; Garanti, L.; Molteni, G.; Zecchi, G. Heterocycles 1997, 45, 1945.

17. Del Buttero, P.; Molteni, G.; Mondini, S.; Ponti, A. Heterocycles 2007, 71, 1095.

18. Broggini, G.; Molteni, G. J. Chem. Soc., Perkin Trans. 1 2000, 1685.

19. Padwa, A.; Craig, S. P.; Chiacchio, U.; Kline, D. N. J. Org. Chem. 1988, 53, 2232.

20. Bruché, L.; Zecchi, G. J. Heterocycl. Chem. 1983, 20, 1705.

21. Bordwell, F. G.; Pagani, G. A. J. Am. Chem. Soc. 1975, 97, 118.

22. Braverman, S. In Chemistry of Sulphones and Sulphoxides; Patai, S. Ed.; John Wiley \& Sons: New York, 1998, pp 670.

23. Molteni, G.; Ponti, A. Tetrahedron 2003, 59, 5225.

24. Molteni, G.; Garanti, L. Heterocycles 2001, 55, 1573.

25. (a) Fétizon, M.; Golfier, M.; Mourgues, P. Tetrahedron Lett. 1972, 13, 4445. (b) Kakis, F. J.; Fétizon, M.; Douchkine, N.; Golfier, M.; Mourgues, P.; Prange, T. J. Org. Chem. 1974, 39, 523.

26. Broggini, G.; Garanti, L.; Molteni, G.; Zecchi, G. Heterocycles 2000, 53, 917.

27. Samarendra, C. I.; Maiti, N.; Micetich, R.; Daneshtalab, M.; Atchison, K.; Phillips, O. A.; Kunugita, C. J. Antibiot. 1994, 47, 1030.

28. Frígola, J.; Colombo, A.; Parés, J.; Martínez, L.; Sagarra, R.; Roser, R. Eur. J. Med. Chem. 1989, 24, 435.

29. Del Buttero, P.; Molteni, G.; Pilati, T. Tetrahedron Lett. 2003, 44, 1425.

30. Del Buttero, P.; Molteni, G.; Pilati, T. Tetrahedron 2005, 61, 2413.

31. (a) Padwa, A. In 1,3-Dipolar Cycloaddition Chemistry; Padwa, A. Ed.; Wiley-Interscience: New York, 1984, Vol. 2, Ch. 12, pp 277. (b) Padwa, A. In Advances in Cycloaddition; Curran, D. P. Ed.; JAI Press: London, 1990, pp 1.

32. Illuminati, G.; Mandolini, L. Acc. Chem. Res. 1981, 14, 95.

33. Kenda, A. S.; Journet, M. Tetrahedron Lett. 1995, 36, 3087.

34. Zecchi, G. Trends in Heterocyclic Chemistry 1991, 2, 85.

35. Broggini, G.; Garanti, L.; Molteni, G., Zecchi, G. J. Chem. Soc., Perkin Trans. 1 1998, 4103.

36. Broggini, G.; Molteni, G., Zecchi, G. J. Chem. Res. 1998, $810(S)$.

37. Broggini, G.; Garanti, L.; Molteni, G.; Zecchi, G. Heterocycles 2000, 53, 831.

38. Molteni, G.; Mondini, S.; Ponti, A. Heterocycles 2007, 71, 1371.

39. Broggini, G.; Garanti, L.; Molteni, G.; Zecchi, G. Heterocycles 1994, 38, 1601.

40. Molteni, G. J. Chem. Res. 1998, $40(S)$.

41. Broggini, G.; Garanti, L.; Molteni, G., Zecchi, G. Org. Prep. Proc. Int. 1996, $28,699$.

42. Broggini, G.; Bruché, L.; Garanti, L.; Zecchi, G. J. Chem. Soc., Perkin Trans. 1 1994, 433.

43. Broggini, G.; Garanti, L.; Molteni, G., Zecchi, G. J. Chem. Res. 1995, 385 (S), 2389 (M).

44. Bruché, L.; Zecchi, G. Tetrahedron 1989, 23, 7427. 
45. Garanti, L.; Sala, A.; Zecchi, G. J. Org. Chem. 1975, 40, 2403.

46. Broggini, G.; Garanti, L.; Molteni, G., Zecchi, G. Tetrahedron 1997, 53, 3005.

47. Broggini, G.; Garanti, L.; Molteni, G., Zecchi, G. Tetrahedron 1998, 54, 2843.

48. Kim, B. H.; Jeong, E. J.; Jung, W. H. J. Am. Chem. Soc. 1995, 117, 6390.

49. Molteni, G.; Pilati, T.; Ponti, A. Tetrahedron 2003, 59, 9315.

50. (a) Molteni, G. Heterocycles 2005, 65, 2516. (b) Pellissier, H. Tetrahedron 2007, 63, 3235.

51. De Benassuti, L.; Garanti, L.; Molteni, G. Tetrahedron 2004, 60, 4627.

52. (a) Garanti, L.; Molteni, G.; Pilati, T. Tetrahedron: Asymmetry 2002, 13, 1285. (b) Pilati, T.; Casalone, G. Acta Cryst. Sect. C 2002, C58, o178.

53. Broggini, G.; Molteni, G.; Zecchi, G. Heterocycles 1998, 47, 541.

54. Garanti, L.; Sala, A.; Zecchi, G. Synth. Commun. 1976, 6, 269.

55. Broggini, G.; Garanti, L.; Molteni, G.; Zecchi, G. Tetrahedron: Asymmetry 1999, $10,487$.

56. Broggini, G.; Molteni, G.; Pilati, T.; Zecchi, G. Synth. Commun. 2001, 31, 3799.

57. Del Buttero, P.; Molteni, G. Tetrahedron: Asymmetry 2006, 17, 1319.

58. Waltser, A.; Fryer, R. J. Bicyclic Diazepines, John Wiley, New York, 1991.

59. Broggini, G.; Garanti, L.; Molteni, G.; Pilati, T.; Ponti, A.; Zecchi, G. Tetrahedron: Asymmetry 1999, 10, 2203.

60. Broggini, G.; Casalone, G.; Garanti, L.; Molteni, G.; Pilati, T.; Zecchi, G. Tetrahedron: Asymmetry 1999, 10, 4447.

61. Broggini, G.; Garanti, L.; Molteni, G.; Pilati, T. Synth. Commun. 2001, 31, 2649.

62. Molteni, G.; Pilati, T. Tetrahedron: Asymmetry 1999, 10, 3873.

63. Broggini, G.; Molteni, G.; Pilati, T. Tetrahedron: Asymmetry 2000, 11, 1975. 


\section{Authors' biographical data}

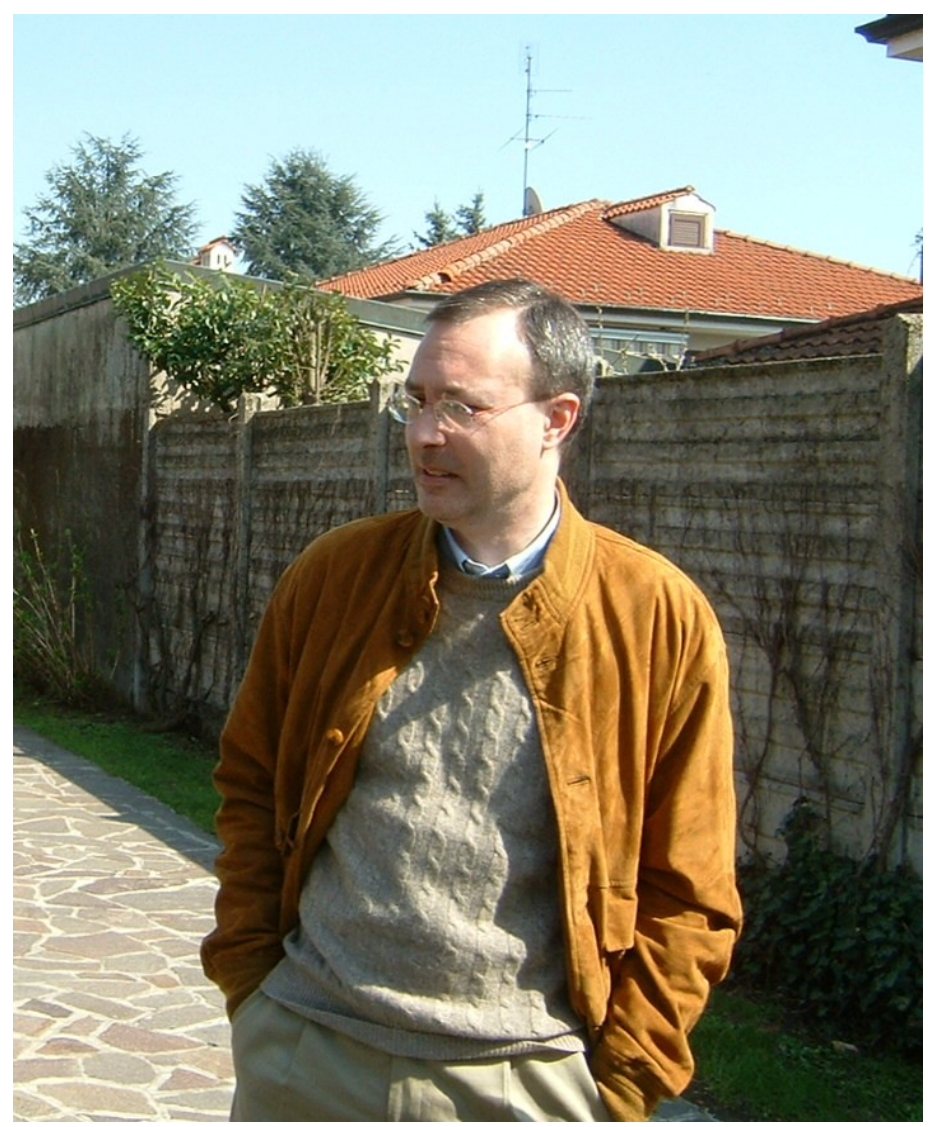

Giorgio Molteni, Ph.D. was born in 1963. He graduated in chemistry at the University of Milan with Prof. Gaetano Zecchi and received his Ph.D. in 1995 at this university under the guidance of Prof. Luisa Garanti, conducting research in the field of intramolecular 1,3-dipolar cycloadditions. From the same year he worked as technician in the Departement of Organic Chemistry, and in 2002 he was appointed researcher at the University of Milan. His current interests focus on the 1,3-dipolar cycloadditions in aqueous media, the computational prediction of cycloaddition outcome and the development of functionalised nanometre-sized metal and metal oxide particles. He is lecturer of Reaction Mechanism in Organic Chemistry (Physical Organic Chemistry) at the University of Milan, and he published more than 80 papers and review articles in the field of 1,3-dipolar cycloaddition chemistry. 